\title{
Comparing mobile and static assessment of biomass in heterogeneous grassland with a multi-sensor system
}

\author{
Hanieh Safari, Thomas Fricke, Björn Reddersen, Thomas Möckel, and Michael Wachendorf \\ Department of Grassland Science and Renewable Plant Resources, University of Kassel, Steinstraße 19, \\ 37213 Witzenhausen, Germany
}

Correspondence to: Hanieh Safari (safari.hanieh@gmail.com) and Michael Wachendorf (gnr@uni-kassel.de)

Received: 18 May 2016 - Revised: 13 July 2016 - Accepted: 16 July 2016 - Published: 2 August 2016

\begin{abstract}
The present study aimed to test a mobile device equipped with ultrasonic and spectral sensors for the assessment of biomass from diverse pastures and to compare its prediction accuracy to that from static measurements. Prediction of biomass by mobile application of sensors explained $>63 \%$ of the variation in manually determined reference plots representing the biomass range of each paddock. Accuracy of biomass prediction improved with increasing grazing intensity. A slight overestimation of the true values was observed at low levels of biomass, whereas an underestimation occurred at high values, irrespective of stocking rate and years. Prediction accuracy with a mobile application of sensors was always lower than when sensors were applied statically. Differences between mobile and static measurements may be caused by position errors, which accounted for $8.5 \mathrm{~cm}$ on average. Beside GPS errors $( \pm 1-2 \mathrm{~cm}$ horizontal accuracy and twice that vertically), position inaccuracy predominantly originated from undirected vehicle movements due to heaps and hollows on the ground surface. However, the mobile sensor system in connection with biomass prediction models may provide acceptable prediction accuracies for practical application, such as mapping. The findings also show the limits even sophisticated sensor combinations have in the assessment of biomass of extremely heterogeneous grasslands, which is typical for very leniently stocked pastures. Thus, further research is needed to develop improved sensor systems for supporting practical grassland farming.
\end{abstract}

\section{Introduction}

Pasture biomass and its quality are a matter of primary concern in continuous grazing systems (Silvia Cid et al., 1998; Kristensen et al., 2005; Oudshoorn et al., 2013). On-site and on-time information on biomass and its spatial distribution in pastures is needed for site-specific pasture management and can help livestock managers in making critical decisions in terms of planning grazing time, grazing period, grazing interval, stocking rate and inputs such as fertilizers (Suzuki et al., 2012). However, conventional plant sampling techniques are costly, destructive and time-consuming, thereby limiting the number of measured samples and being impractical for characterizing spatial variability in sward characteristics within fields (Fava et al., 2009). In contrast, real-time mobile sensors, which allow the collection of geographically referenced data, have proven to be useful for in-field monitoring of vegetation characteristics with high spatial reso- lution (Lan et al., 2009; Muñoz-Huerta et al., 2013; Cozzolino et al., 2015). Mobile automated sensor measurements can provide high sampling density at a relatively low cost to generate maps representing both spatial and temporal variations (Adamchuk et al., 2004). Farooque et al. (2013) developed an integrated automated system comprising an ultrasonic sensor, a digital color camera, a slope sensor and a global positioning system (GPS) to measure plant height, fruit yield, slope and elevation in wild blueberry fields and concluded the developed system was accurate, reliable and efficient to map such characteristics in real-time kinematics (RTK). Pittman et al. (2015) examined several types of ground-based mobile-sensing strategies (ultrasonic, laser and spectral sensors) to estimate biomass and canopy height in Bermuda grass, alfalfa and wheat. They suggested that using mobile-sensor-based biomass estimation methods could be an effective alternative to the traditional clipping method 
for a rapid and accurate in-field biomass estimation. Different types of sensors both in static and mobile application have been used in recent grassland studies (Numata et al., 2008; Biewer et al., 2009a, b; Himstedt et al., 2009; Kawamura et al., 2009; Fricke et al., 2011; Pullanagari et al., 2012; Duan et al., 2014; Rahman et al., 2014; Reddersen et al., 2014). Particularly hyperspectral sensors, which measure reflectance signals over a wide range of wavelengths in discrete bands of $1-15 \mathrm{~nm}$ width, have raised considerable interest for the prediction of biomass and quality parameters. However, pastures are highly heterogeneous ecosystems due to variations in canopy architecture, botanical composition and phenological stage of plants. Hence, the application of sensors in grazed pastures is more difficult than in cut grassland, and there are limitations for each specific sensor technique used for the prediction of sward characteristics (Schellberg et al., 2008; Pullanagari et al., 2012). An effective method for in-field estimation of biomass must reach an accuracy comparable to the accepted standard of destructive procedure (clipping and weighing) (Pittman et al., 2015). Using a data combination of conceptually different sensing methods holds promise for providing more accurate property estimates (Adamchuk et al., 2004). A sensor fusion approach has been proposed that combines measured sward height with an ultrasonic distance sensor and vegetation indices (VIs) derived from spectral-radiometric reflections to estimate biomass in grasslands with acceptable prediction accuracies (Fricke and Wachendorf, 2013; Reddersen et al., 2014; Safari et al., 2015). The guiding idea in this approach is that canopy reflectance provides complementary information to canopy height sensing when estimating biomass. In all studies best prediction accuracies were achieved by a combination of ultrasonic sward height (USH) and sward-specific band selection using the normalized spectral vegetation index (NDSI, which uses two spectral bands best suited for estimating biomass according to normalized difference vegetation index (NDVI) formula) with $R^{2}$ values of 0.63 to 0.90 . The selection of two narrow or broad bands from hyperspectral data has an advantage for practical implementation at field scale, as multispectral measurements are less expensive than hyperspectral ones. Likewise, ultrasonic sensors are simple and cost-effective equipment but nevertheless may provide accurate and real-time information needed by farmers to make on-farm decisions. However, no knowledge exists on how accurately such sensors work when applied on mobile devices and which position accuracy can be achieved under real field conditions.

The overall aim of the present study was to develop and test a mobile sensor system equipped with ultrasonic and spectral sensors and a high-precision GPS to assess data in experimental pastures with a large variation of spatial and phenological structures. The following specific research questions were addressed in this study: (i) which overall prediction accuracy for grassland biomass can be achieved? (ii) Is there a reduction in prediction accuracy between static
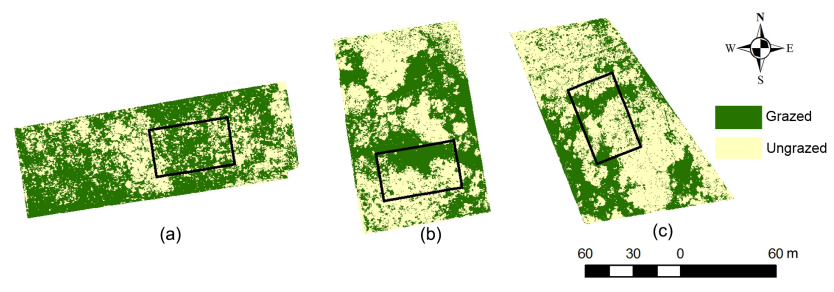

Figure 1. Images with digitally classified grazed and ungrazed areas in grassland paddocks of different stocking rate: (a) moderate, (b) lenient and (c) very lenient. Black boxes indicate the location of $30 \times 50 \mathrm{~m}$ study plots. Photos were taken in April 2013 .

and mobile application of sensors? (iii) Does the performance of the sensor system depend on the grazing intensity? (iv) What are possible position errors associated with mobile sensor measurements?

\section{Material and methods}

\subsection{Experimental site and setup}

The study was conducted in a long-term pasture experiment (established in 2002) at the experimental farm Relliehausen $\left(51^{\circ} 46^{\prime} 55^{\prime \prime} \mathrm{N}, 9^{\circ} 42^{\prime} 13^{\prime \prime} \mathrm{E}, 180-230 \mathrm{~m}\right.$ above mean sea level) in Solling Uplands on moderately species rich grasslands, vegetation type Lolio-Cynosuretum. Three target paddocks of 1 ha each with different continuous stocking treatments were selected from the experiment. Treatments were (a) moderate stocking, with an average of 3.4 standard livestock units (SLUs, i.e., $500 \mathrm{~kg}$ live weight) $\mathrm{ha}^{-1}$; (b) lenient stocking, with an average $1.8 \mathrm{SLU} \mathrm{ha}^{-1}$; and (c) very lenient stocking, with an average 1.3 $\mathrm{SLU} \mathrm{ha}^{-1}$ (Wrage et al., 2012). In each paddock one study plot of $30 \times 50 \mathrm{~m}$ size was established, to represent spatial variability in pastures under different grazing intensities during 2-year measurements. The location of the study plots was determined prior to field sampling in a geographic information system (GIS) environment (ArcGIS 9.2). In a first step aerial photographs of each paddock were obtained in April 2013 using a remotely controlled Hexacopter carrying a small, lightweight camera. The photos were georeferenced along GPS-levelled boundaries of each paddock, and the area of each paddock was classified into grazed and ungrazed areas using a visually adapted green-yellow threshold (Fig. 1). The portion of both areas was then calculated for each paddock $(63,47$ and $38 \%$ classified as grazed areas in moderate, lenient and very lenient paddocks, respectively). Rectangles of $30 \times 50 \mathrm{~m}$, representing the study plots, were moved in the paddock area using GIS until they contained identical portions of grazed and ungrazed areas as in the surrounding paddock. Each study plot was accurately located in the field by differential GPS (DGPS) and marked with corner poles. Field measurements for static and mobile calibration of the sensor system were conducted in 2013 on 3-5 June and 2014 on 20-22 May. 


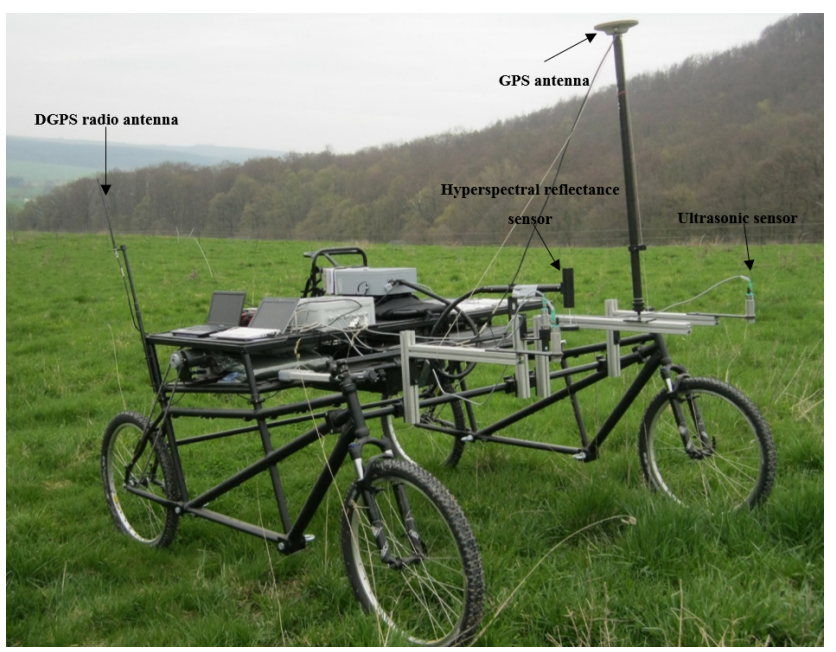

Figure 2. Remotely steered sensor vehicle with hyperspectral reflectance, ultrasonic sensors and mounted GPS antenna.

\subsection{Mobile measurements on the study plots}

The multi-sensor system consisted of ultrasonic distance and hyperspectral reflectance sensors. The ultrasonic sensor holds a one-headed system (Pepperl and Fuchs, type UC 2000-30GM-IUR2-V15) operating with a transducer frequency of $180 \mathrm{~Hz}$ (Pepperl and Fuchs, 2010). Distances were measured in a range from 80 to $2000 \mathrm{~mm}$ within a sound cone formed by an opening angle of about $25^{\circ}$. Ultrasonic sward height $(\mathrm{mm})$ was calculated by subtracting the ultrasonic distance measurement value in millimeters from the sensor mount height using Eq. (1):

$$
\begin{aligned}
\operatorname{USH}(\mathrm{cm})= & \text { mount height }(\mathrm{cm}) \\
& - \text { ultrasonic distance }(\mathrm{cm}) .
\end{aligned}
$$

A HandySpec Field portable spectrometer (tec5 AG, Oberursel, Germany) was used to measure canopy spectral reflectance. The measuring head of the device had two channels measuring incoming and reflected radiation simultaneously between 305 and $1700 \mathrm{~nm}$ in $1 \mathrm{~nm}$ steps. Spectral calibrations were performed using a grey standard (Zenith Polymer ${ }^{\circledR}$ Diffuse Reflectance Standard $25 \%$ ) at fixed intervals. Both sensor systems provided the same opening angle with a field of view (FOV) of $25^{\circ}$. While the spectral sensor measures an integrated value of reflection intensity within the measurement cone, the ultrasonic sensor measure the highest object, creating a reliable reflection within the sound cone.

Mobile measurements were conducted using an electrically driven cycle-based four-wheel-vehicle with a track gauge of $180 \mathrm{~cm}$ (Fig. 2). Both sensors were mounted at the front-end center of the vehicle on a frame, allowing measurements along the central track during the vehicle movements. Two more ultrasonic sensors were mounted with $60 \mathrm{~cm}$ distance on either side of the central sensor to allow a higher measurement density for future mapping activities. GPS po- sitions of all sensor readings were acquired in $0.1 \mathrm{~s}$ intervals using a Leica SR530 dual-frequency geodetic RTK receiver. A GPS AT 502 dual-frequency antenna was mounted on top of a pole close to the sensors. Its geometric position in relation to both the ground and the sensors was recorded and considered in subsequent sensor position calculations including a correction of topographically induced antenna pole skewness. The DGPS correction signals were received from an on-field reference station at a maximum distance of $500 \mathrm{~m}$ by a radio modem. Both the reference station and rover were equipped with components of identical technical specifications, providing a horizontal positional accuracy of 1-2 and $2-3 \mathrm{~cm}$ vertical accuracy. For mobile measurements the vehicle was remotely steered along $50 \mathrm{~m}$ longitudinal lanes in the study plots at a speed of approximately $0.1-0.3 \mathrm{~m} \mathrm{~s}^{-1}$. Ultrasonic measurements were triggered at a $0.3 \mathrm{~s}$ interval, resulting in a measured point distance of $10 \pm 6 \mathrm{~cm}$ (mean of all plots). Spectral reflections were continuously assessed; however with a variable data integration time of the spectrometer between 1 and $5 \mathrm{~s}$, measurements were logged discontinuously, corresponding to a measured distance of $43 \pm 20 \mathrm{~cm}$ between spectral measurement points in each plot (mean of all plots).

\subsection{Static measurements on reference plots}

Subsequent to the mobile measurement, 18 reference plots (each $50 \times 50 \mathrm{~cm}$ ) were established within each of the three study plots by positioning them along the central axis between the vehicle tracks to represent the occurring range of available biomass levels and sward structures. Static sensor measurements were conducted on these reference plots using the same sensors as in the mobile measurement and following the methodology as described by Fricke et al. (2011). The total aboveground biomass from each reference plot was clipped at ground surface level after sensor measurements were taken. In the present study grassland biomass is expressed as the amount of fresh matter (FM) in grams per square meter $\left(\mathrm{g} \mathrm{m}^{-2}\right)$. To avoid repeated sampling at the same position across time, the location of reference plots was determined using DGPS.

\subsection{Data integration and analysis}

Spectral calibration models were developed for each year separately in order to reach the maximum prediction accuracy using biomass data from reference plots. In an attempt to create prediction models with maximum accuracy by using the depth of information of hyperspectral data, narrowband NDSIs according to Inoue et al. (2008) were applied over the range of $1 \mathrm{~nm}$ spectral bandwidths using all possible combinations of two-band reflectance ratios based on NDVI formula according to Eq. (2):

$\operatorname{NDSI}\left(b_{1}, b_{2}\right)=\left(b_{1}-b_{2}\right) /\left(b_{1}+b_{2}\right)$, 
Table 1. Summary statistics of static and mobile measurements of ultrasonic sward height (USH) $(\mathrm{cm})$ and normalized difference spectral index (NDSI) on reference plots of pastures with different stocking rates in 2013 and 2014.

\begin{tabular}{|c|c|c|c|c|c|c|c|c|}
\hline & \multicolumn{4}{|c|}{ Static measurements } & \multicolumn{4}{|c|}{ Mobile measurements } \\
\hline & \multicolumn{2}{|c|}{2013} & \multicolumn{2}{|c|}{2014} & \multicolumn{2}{|c|}{2013} & \multicolumn{2}{|c|}{2014} \\
\hline & USH & NDSI & USH & NDSI & USH & NDSI & USH & NDSI \\
\hline \multicolumn{9}{|c|}{ Moderate ( $n=18$ in each year) } \\
\hline Min & 3.1 & 0.031 & 9.0 & -0.030 & 4.7 & 0.032 & 12.0 & -0.032 \\
\hline Mean & 21.9 & 0.046 & 26.8 & -0.017 & 22.1 & 0.048 & 30.0 & -0.020 \\
\hline Max & 50.6 & 0.065 & 64.0 & -0.008 & 60.9 & 0.063 & 67.4 & -0.015 \\
\hline SD & 14.5 & 0.011 & 13.6 & 0.005 & 14.8 & 0.010 & 14.2 & 0.004 \\
\hline \multicolumn{9}{|c|}{ Lenient ( $n=18$ in each year) } \\
\hline Min & 24.8 & 0.027 & 16.4 & -0.021 & 22.9 & 0.030 & 19.2 & -0.020 \\
\hline Mean & 44.3 & 0.038 & 32.5 & -0.015 & 46.1 & 0.040 & 37.3 & -0.013 \\
\hline Max & 64.0 & 0.049 & 55.4 & -0.008 & 75.6 & 0.057 & 61.2 & -0.007 \\
\hline SD & 12.3 & 0.006 & 10.6 & 0.004 & 16.2 & 0.008 & 12.7 & 0.004 \\
\hline \multicolumn{9}{|c|}{ Very lenient ( $n=18$ in each year) } \\
\hline Min & 10.0 & 0.032 & 7.2 & -0.020 & 8.7 & 0.029 & 11.6 & -0.032 \\
\hline Mean & 43.1 & 0.047 & 29.8 & -0.011 & 48.9 & 0.048 & 36.9 & -0.011 \\
\hline $\operatorname{Max}$ & 64.6 & 0.065 & 58 & -0.007 & 75.2 & 0.070 & 66.5 & -0.005 \\
\hline SD & 16.0 & 0.011 & 15.8 & 0.00 & 19.5 & 0.009 & 17.1 & 0.007 \\
\hline \multicolumn{9}{|c|}{ All pastures ( $n=54$ in each year) } \\
\hline Min & 3.1 & 0.027 & 7.2 & -0.030 & 4.7 & 0.029 & 11.6 & -0.032 \\
\hline Mean & 36.4 & 0.044 & 29.7 & -0.014 & 39.0 & 0.046 & 34.7 & -0.015 \\
\hline Max & 64.6 & 0.065 & 64.0 & -0.007 & 75.6 & 0.070 & 67.4 & -0.005 \\
\hline SD & 17.5 & 0.010 & 13.5 & 0.005 & 20.2 & 0.010 & 14.9 & 0.006 \\
\hline
\end{tabular}

where $b_{1}$ and $b_{2}$ are specific narrowband $(1 \mathrm{~nm})$ reflection signals with wavelength $b_{1}>$ wavelength $b_{2}$.

All possible two-pair $1 \mathrm{~nm}$ band combinations in the hyperspectral range from 360 to $1340 \mathrm{~nm}$ and 1500 to $1650 \mathrm{~nm}$ were tested. Ordinary least-squares regression analysis (Ryan, 1997) was performed using a linear model procedure in R (version 3.0.2) (R Development Core Team, 2013) with biomass as the dependent variable and NDSI together with USH as independent variables including interactions and quadratic terms according to Eq. (3):

$$
\begin{gathered}
B=\mathrm{USH}+\mathrm{NDSI}+\mathrm{USH} \cdot \mathrm{NDSI}+\mathrm{USH}^{2}+\mathrm{USH}^{2} \\
\cdot \mathrm{NDSI}+\mathrm{NDSI}^{2}+\mathrm{USH} \cdot \mathrm{NDSI}^{2}+\mathrm{USH}^{2} \cdot \mathrm{NDSI}^{2},
\end{gathered}
$$

where $B$ is biomass $\left(\mathrm{g} \mathrm{FM} \mathrm{m}^{-2}\right.$ ) and USH is in centimeters.

NDSI wavebands were considered adequate when $R^{2}$ of the model was maximum. According to the rules of hierarchy and marginality (Nelder, 1994) non-significant effects were excluded from the models but were retained if the same variable appeared as part of a significant interaction at $\alpha$ level of $5 \%$. Calibration models were validated by a fourfold crossvalidation method (Diaconis and Efron, 1983).

\subsection{Assessment of position accuracy}

With the aim of establishing a plausibility control for position accuracy of mobile measurements, an additional experiment was set up. Wooden planks of known position and dimension at each end of the vehicle tracks were measured in spring, before the vegetation started to grow. Thus, higher targets could be clearly distinguished from lower swards. Vehicle measurement were conducted in the same mode as described above. Here, only USH data were used due to their high point density. Measured values were compared to expected values and classified as error if a discrepancy was observed. The distance of an erroneous measurement to the closest apparent target edge (considering target dimensions and sensor properties) was assigned to the respective measurement and used for subsequent spatial analysis. Further information on the methodology is provided in the Appendix.

\section{Results and discussion}

\subsection{Relationship between static and mobile sward measurements for use of exclusive sensors}

Statically measured USH ranged from 3.1 to $64.6 \mathrm{~cm}$ and from 7.2 to $64.0 \mathrm{~cm}$ in 2013 and 2014, respectively (Table 1). Compared to static measurements higher values of USH were found by mobile application ranging from 4.7 to $75.6 \mathrm{~cm}$ and from 11.6 to $67.4 \mathrm{~cm}$ in 2013 and 2014, respectively. This may be the effect of a crossbar which was attached to the rear of the vehicle at a height of about $50 \mathrm{~cm}$ for stabilizing purposes and may have compressed higher vegetation during vehicle passage, and subsequent static measurements were possibly influenced by that. Pastures with a moderate stocking rate exhibited lower USH values (mean value $=21.9$ and $26.8 \mathrm{~cm}$ in 2013 and 2014, respectively) compared to pastures with a lenient stocking rate (mean value $=44.3$ and $32.5 \mathrm{~cm}$ in 2013 and 2014, respectively) and very lenient stocking rate (mean value $=43.1$ and $29.8 \mathrm{~cm}$ in 2013 and 2014, respectively). Swards of the latter two stocking rates showed similar USH levels in both years, although pastures were managed and monitored by the use of a compressed sward height meter (CSH; according Castle, 1976), maintaining levels at $6 \mathrm{~cm}$ (moderate), $12 \mathrm{~cm}$ (lenient) and $18 \mathrm{~cm}$ (very lenient) (Wrage et al., 2012). This disparity may indicate the influence of sward structure on the conducted measurement methods: while CSH reflects the resistance of biomass according to stem density and sward height (Hakl et al., 2012), USH predominantly detects protruding objects regardless of other sward conditions in subordinate layers (Fricke et al., 2011). This fact indicates the limitations of biomass predictions based on pure USH, as it may not directly reflect the biomass, particularly if swards are composed by plants of varying phenology, which is common in leniently grazed swards (Rook and Tallowin, 2003; Wrage et al., 2011).

NDSI wavelength locations associated with maximum accuracy of biomass prediction differed between years. Positive NDSI values in 2013 corresponded to the green peak of the spectrum (at 536 and $564 \mathrm{~nm}$, on the ascending slope), 

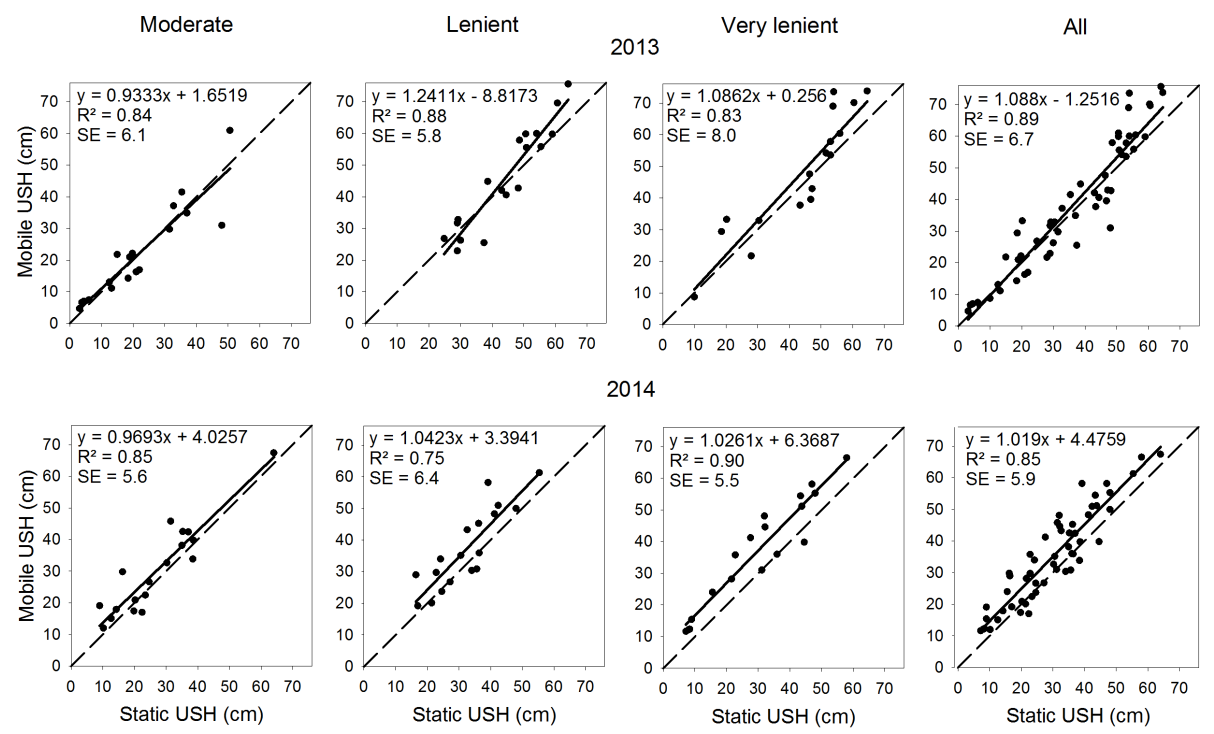

2014

$$
\begin{aligned}
& \text { - Mobile USH vs. static USH } \\
& - \text { Regression line } \\
& ---y=x
\end{aligned}
$$

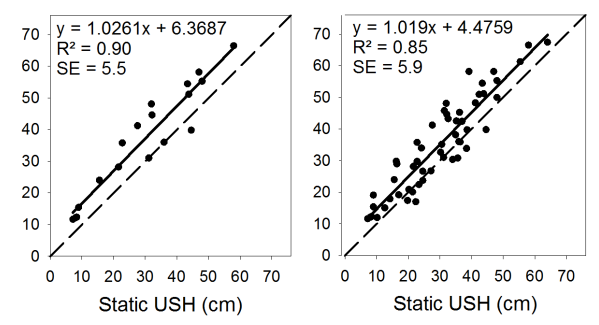

Figure 3. Relationship between mobile- and statically measured ultrasonic sward height (USH) (cm). Both measurements were conducted on reference plots in pastures differently stocked with animals in 2013 and 2014.

while negative values in 2014 corresponded to the descending slope of the second water absorption band (at 1121 and $1133 \mathrm{~nm}$ ). NDSI values by static measurement ranged from 0.027 to 0.065 with a mean value of 0.044 across all pastures in 2013, which were slightly lower than the values by mobile application (mean value $=0.046$ ). In 2014 a smaller range of NDSI values occurred by both static and mobile application $(-0.030$ to -0.007$)$, resulting in a mean value of -0.014 (Table 1).

USH values from mobile measurements were in good agreement with static values, with $R^{2} \geq 0.85$ for all pastures in both years (Fig. 3). This indicates that reliable and accurate USH information could be acquired by the mobile application of low-cost ultrasonic sensors. Moreover, it seems that the performance of the mobile application is not affected by the stocking rate, as $R^{2}$ values differed only randomly during the 2-year measurements on different pastures.

The relationship between NDSI values determined on the reference plots by mobile and static application was closer for moderate $\left(R^{2}=0.66-91\right)$ than for leniently and very leniently grazed pastures $\left(R^{2}=0.59-0.72\right)$ (Fig. 4). This may be partly due to a higher proportion of senesced material in pastures at lower grazing intensities. This is supported by results of Safari et al. (2015), which showed a lower accuracy of spectral calibrations for grassland biomass in the second half of the growing season, when senesced material likewise presented greater shares of the grassland canopy. Botanical diversity, which is well known to increase with reduced defoliation intensity through grazing or cutting (Blüthgen et al., 2012; Isselstein et al., 2005), may have further alleviated the relationship between grassland biomass and spectral characteristics. For the biomass of species-poor grasslands, spectral calibrations based on static measurements frequently achieved higher accuracies than for less intensively grazed swards (Biewer et al., 2009a; Reddersen et al., 2014). Compared to ultrasonic measurements, accuracy of spectral calibrations was remarkably lower in both years and at all levels of grazing intensity. One reason may be the lower measurement point density of spectral (1.3 per plot on average) than ultrasonic recordings (5.0 per plot on average), which can be explained by the lower data integration time for the former technique. In pastures with high canopy variability (lenient and very lenient), where extremely short (intensively grazed) and tall (lightly grazed) patches are frequently located in the immediate vicinity of each other, a high measurement point density is of particular benefit. This may explain why in moderately grazed pastures the accuracy of NDSI is only $7 \%$ lower than USH (averaged over both years), whereas under very leniently grazing the accuracy of NDSI is $24 \%$ lower.

\subsection{Relationship between static and mobile sward measurements for sensor combination}

Calibrations used in the present study were developed in a recent study by Safari et al. (2015) and showed cross-validation errors for biomass of pastures of 340 and $287 \mathrm{~g} \mathrm{FM} \mathrm{m}^{-2}$ in 2013 and 2014, respectively (Table 2). The best-fit two-pair wavelengths for prediction of biomass were located in the 

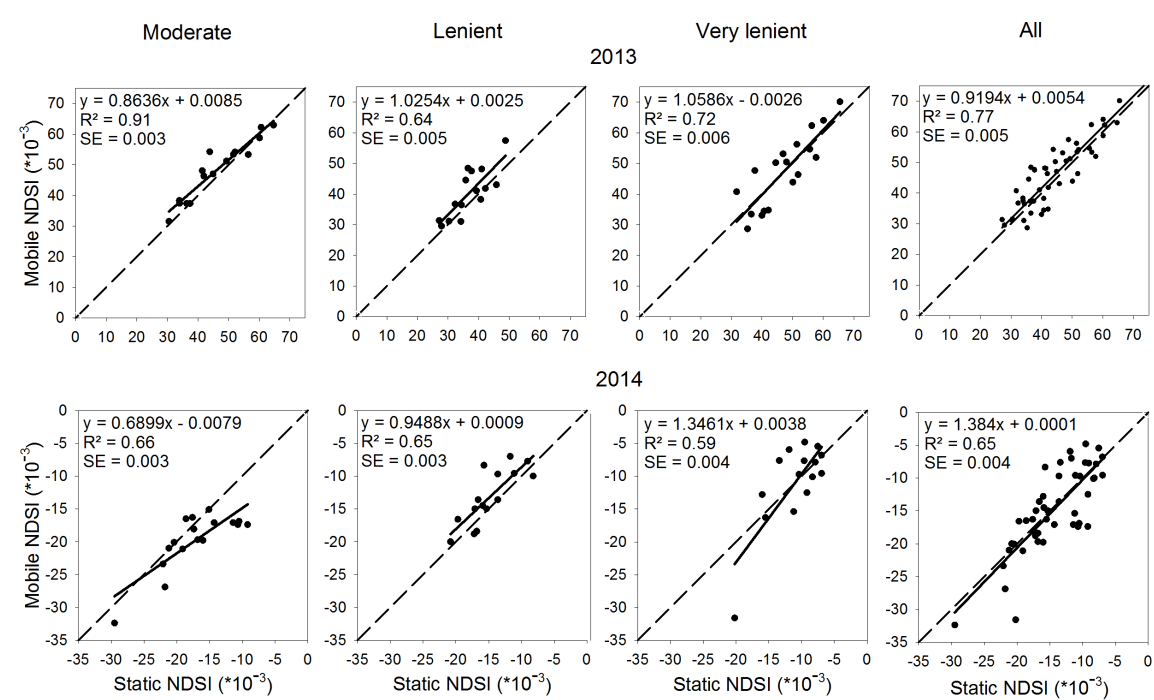

$$
2014
$$
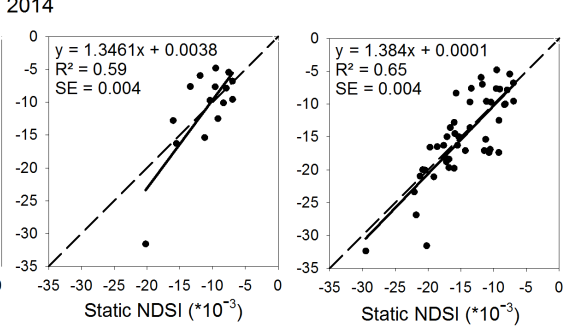

$$
\begin{aligned}
& \text { - Mobile NDSI vs. static NDSI } \\
& - \text { Regression line } \\
& ---y=x
\end{aligned}
$$

Figure 4. Relationship between mobile- and statically measured normalized difference spectral index (NDSI). Both measurements were conducted on reference plots in pastures differently stocked with animals in 2013 and 2014.

\begin{tabular}{|c|c|c|c|c|c|c|c|}
\hline Year & $b_{1}$ & $b_{2}$ & $R^{2}$ & $\begin{array}{r}\mathrm{SE} \\
\left(\mathrm{g} \mathrm{FM} \mathrm{m}^{-2}\right)\end{array}$ & $R_{\mathrm{CV}}^{2}$ & $\begin{array}{r}\mathrm{RMSE}_{\mathrm{CV}} \\
\left(\mathrm{g} \mathrm{FM} \mathrm{m}^{-2}\right)\end{array}$ & Equation \\
\hline 2013 & 536 & 564 & 0.82 & 344.2 & 0.75 & 340.0 & $\begin{array}{l}B=1664.26-22748.47 \mathrm{NDSI}+56.82 \mathrm{USH}- \\
991.32 \mathrm{NDSI} \times \mathrm{USH}\end{array}$ \\
\hline 2014 & 1121 & 1133 & 0.87 & 227.0 & 0.68 & 287.0 & $\begin{array}{l}B=-271-146000 \mathrm{NDSI}-9330000 \mathrm{NDSI}^{2}-29.5 \mathrm{USH}+ \\
1.89 \mathrm{USH}^{2}-7010 \mathrm{NDSI} \times \mathrm{USH}+361 \mathrm{NDSI} \times \mathrm{USH}^{2}+ \\
11100 \mathrm{NDSI}^{2} \times \mathrm{USH}^{2}\end{array}$ \\
\hline
\end{tabular}

Table 2. Regression and cross-validation statistics of prediction models for biomass $(B)\left(\mathrm{g} \mathrm{FM} \mathrm{m}^{-2}\right)$ from USH (cm) and narrowband NDSI during mobile application. Models were derived from static measurements on reference plots according Eqs. (1) and (2) (see above) $(n=54)$.

$b_{1}, b_{2}=$ spectral bands. $\mathrm{SE}=$ standard error. $\mathrm{RMSE}_{\mathrm{CV}}=$ random mean square error of cross validation.

visible (2013) and near-infrared (NIR) (2014) regions of the spectrum. Several studies have indicated the importance of the visible-near-infrared range to create models for estimating biomass using narrowband ratios (Numata et al., 2008; Psomas et al., 2011; Fricke and Wachendorf, 2013). The 536 and $564 \mathrm{~nm}$ bands from the visible region (2013) can be correlated with chlorophyll content of vegetation (Psomas et al., 2011), while the 1121 and $1133 \mathrm{~nm}$ bands from NIR (2014) are related to plant leaf water content (Raymond, 1991).

Biomass in the reference plots as measured by manual clipping and weighing ranged from 107.2 to 3207.2 and from 360.8 to $2832.0 \mathrm{~g} \mathrm{FM} \mathrm{m}^{-2}$ in 2013 and 2014, respectively (Table 3). In 2013 the leniently stocked pasture showed the highest biomass (mean value $=1727.6 \mathrm{~g} \mathrm{FM} \mathrm{m}^{-2}$ ) compared to the other pastures, while in 2014 reference plots in moderate pasture had the highest biomass (mean value $=1335.8 \mathrm{~g} \mathrm{FM} \mathrm{m}^{-2}$ ), followed by leniently grazed pas- ture (mean value $=1271.6 \mathrm{~g} \mathrm{FM} \mathrm{m}^{-2}$ ). While biomass predicted by static application differed only slightly $(<1 \%)$ from manual clipping (mean of all pastures), values predicted by mobile application were somewhat lower with 3.7 and $7.1 \%$ in 2013 and 2014, respectively.

Biomass prediction by mobile sensors was significantly associated with static sensor predictions and reference data (Fig. 5). With $R^{2}$ values of 0.77 and 0.84 for biomass of all pastures in 2013 and 2014, respectively, the relationship between mobile and static predictions was quite close. Mobile prediction of biomass explained 63 and $76 \%$ of the variation in manually determined reference data of all pastures in 2013 and 2014, respectively. When looking more closely into the data, it becomes apparent that the accuracy of biomass prediction improved with increasing grazing intensity, with $R^{2}$ values of $0.52,0.68$ and 0.73 (average of both years) for very leniently, leniently and moderately grazed pastures, re- 

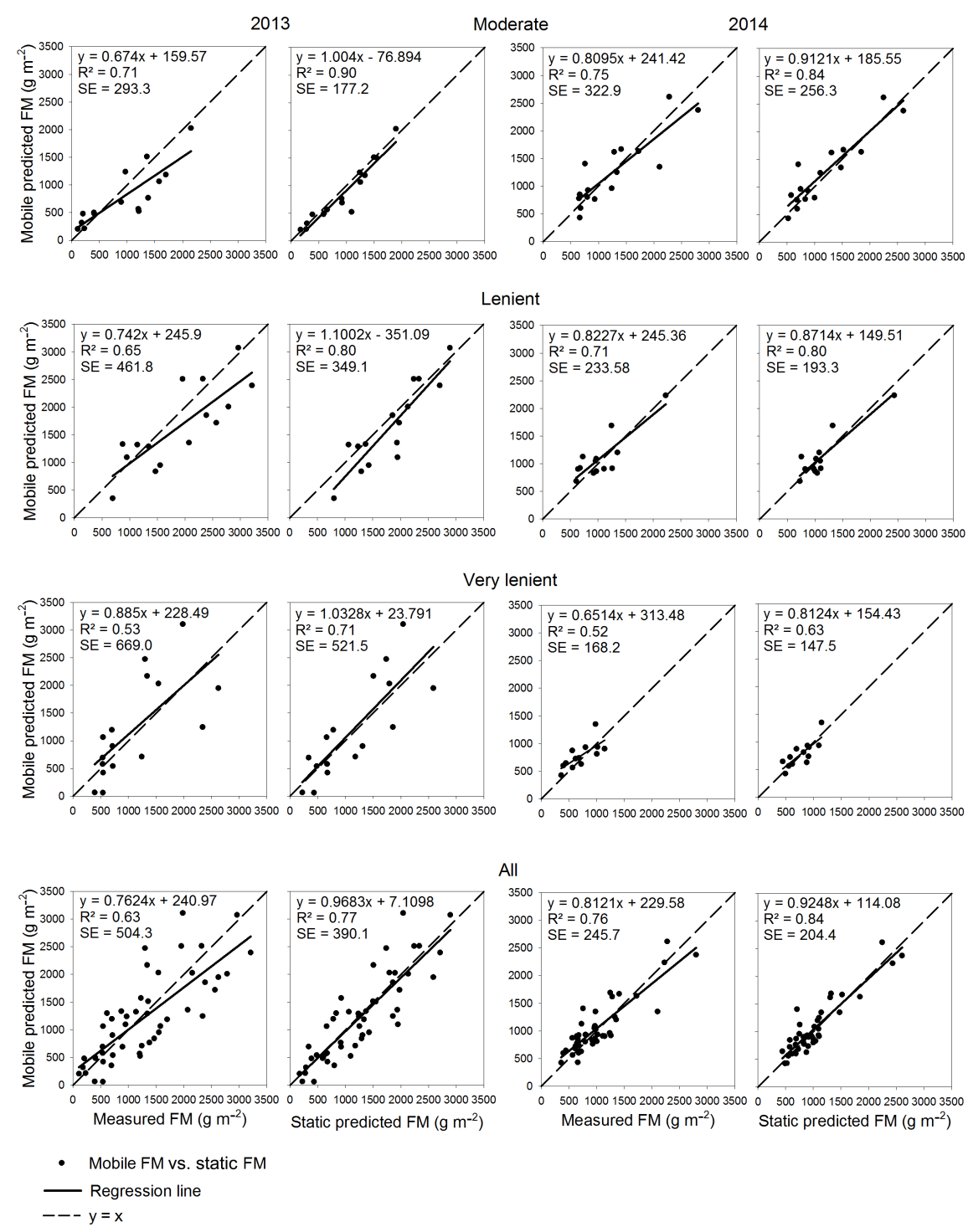

Figure 5. Relationship between mobile- and statically measured biomass ( $\mathrm{g} \mathrm{FM} \mathrm{m}^{-2}$; based on combined sensor data USH and NDSI) and values measured by clipping. All measurements were conducted on reference plots in pastures differently stocked with animals in 2013 and 2014.

spectively. Though sensor combinations proved a higher prediction accuracy for grassland yield and quality compared to exclusive ultrasonic or spectral sensors (Safari et al., 2015, 2016), the findings of the present study likewise show the limits even sensor combinations have in the mobile assessment of biomass of extremely heterogeneous grasslands.

Regression lines in Fig. 5, describing the relationship between actual and mobile-predicted biomass, generally exhibit a slope $<1$, which indicates an overestimation of the true values at low levels of biomass and an underestimation at high values, irrespective of stocking rate and years. The reason for an overestimation at low levels of biomass may be that the sensor system was not capable of grasping extremely high bulk densities accurately, which obviously occur when low swards exhibit high yields.

In such situations bulk density of upper canopy layers is frequently much less than in lower canopy layers, a reason why both sensors may face limitations: on the one side the ultrasonic sensor detects signals reflected predominantly from upper canopy layers (Fricke et al., 2013) largely independent of the actual density of the sward. On the other side the reduction in the amount of radiation penetrating to a greater depth in the canopy can limit reflectance sensors especially in grass-dominated canopies, which have their maximum leaf area index close to the soil surface (Goel, 1988). 
Table 3. Summary statistics of measured and predicted biomass $\left(\mathrm{g} \mathrm{FM} \mathrm{m}^{-2}\right)$ based on predictions by static and mobile application for pastures with different stocking rates in 2013 and 2014.

\begin{tabular}{|c|c|c|c|c|c|c|}
\hline & \multicolumn{3}{|c|}{2013} & \multicolumn{3}{|c|}{2014} \\
\hline & \multirow[t]{2}{*}{ Measured } & \multicolumn{2}{|c|}{ Predicted } & \multirow[t]{2}{*}{ Measured } & \multicolumn{2}{|c|}{ Predicted } \\
\hline & & Static & Mobile & & Static & Mobile \\
\hline \multicolumn{7}{|c|}{ Moderate ( $n=18$ in each year) } \\
\hline Min & 107.2 & 170.4 & 206.4 & 645.6 & 523.6 & 430.4 \\
\hline Mean & 942.8 & 968.7 & 831.6 & 1335.8 & 1279.5 & 1252.7 \\
\hline Max & 2152.0 & 2199.6 & 2028.8 & 2797.6 & 2602.7 & 2615.4 \\
\hline \multicolumn{7}{|c|}{ Lenient ( $n=18$ in each year) } \\
\hline Min & 611.2 & 797.4 & 354.4 & 610.4 & 728.7 & 686.7 \\
\hline Mean & 1727.6 & 1658.7 & 1643.2 & 1271.6 & 1272.6 & 1111.1 \\
\hline Max & 3207.2 & 2892.6 & 3076.0 & 2832.0 & 2433.0 & 2237.2 \\
\hline \multicolumn{7}{|c|}{ Very lenient ( $n=18$ in each year) } \\
\hline Min & 250.4 & 220.9 & 60.8 & 360.8 & 441.6 & 426.9 \\
\hline Mean & 1050.2 & 1093.1 & 1112.5 & 834.1 & 882.8 & 779.7 \\
\hline Max & 2624.0 & 2587.0 & 3109.9 & 1567.2 & 1798.4 & 1349.7 \\
\hline \multicolumn{7}{|c|}{ All pastures ( $n=54$ in each year) } \\
\hline Min & 107.2 & 170.4 & 60.8 & 360.8 & 441.6 & 426.9 \\
\hline Mean & 1240.2 & 1240.2 & 1194.7 & 1147.2 & 1145.0 & 1062.5 \\
\hline Max & 3207.2 & 2892.6 & 3109.9 & 2832.0 & 2602.7 & 2615.4 \\
\hline
\end{tabular}

\subsection{Assessment of position accuracy}

Though equal sensor calibrations were used, variation occurred between static and mobile measurements (Figs. 3 and. 4). Differences may be brought about by vehicle configuration and movement, resulting in sensor displacement and confused geographical location. To evaluate these effects on the position of measuring points, which in this study is important to ensure correct placement of sensor measurements inside the reference plots during vehicle passage, a separate experimental setup was used (see also Appendix). Briefly, position accuracy was analyzed by comparing measured and expected USH values of vehicle measurements in the close surrounding of wooden marks with known dimension and position. Erroneous measurements, classified with respect to target and sensor properties, were assigned to their spatial distance from the target edges. The position error is here expressed as the relative frequency of erroneous measurements within a distance class related to apparent target edges, where a USH change between low and high was expected (Fig. 6).

Error frequency declined with increasing distance from apparent target edges, and the trend indicates a negligible risk of erroneous measurements when the distance between two objects was more than $25 \mathrm{~cm}$. Altogether the average position error was $8.5 \pm 5.8 \mathrm{~cm}$. Beside GPS errors of $1-2 \mathrm{~cm}$, positioning inaccuracy observed in this study predominantly originated from undirected vehicle movements due to heaps and hollows of the ground surface. These errors could be compensated for by a gyroscope, which can level out unbalanced sensor movements caused by the vehicle (Nagasaka et al., 2004). Further, measurement signal processing delays

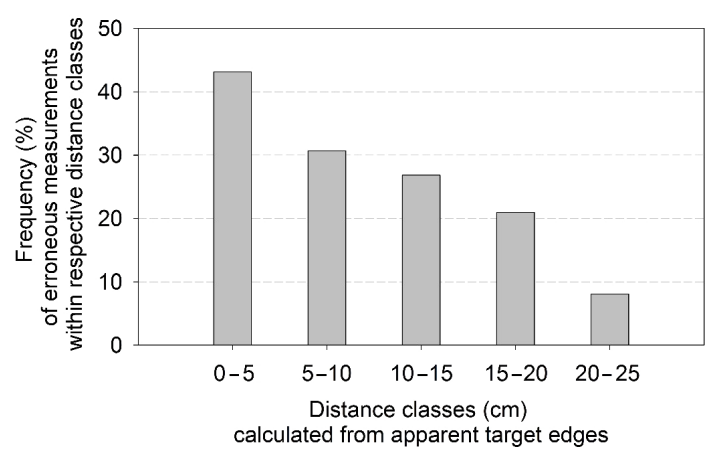

Figure 6. Frequency of erroneous USH measurements (\% of all measurements within a distance class) at different distance from apparent target edges (considering target dimensions and sensor properties).

caused position offsets, which have in part been addressed in other studies but are very specific to the respective vehicle construction. These position offsets could be compensated for by appropriate mathematical models or coefficients in sensor position calculations (Zhao et al., 2010; Gottfried et al., 2012). Hence, although position errors were rather low, there are prospects for a further reduction. Regarding the precision of mobile measurements in the reference sampling plots, about $17 \%$ of the measurements (mean position error of $8.5 \mathrm{~cm}$ divided by sampling plot width of $50 \mathrm{~cm}$ ) can be expected to lie outside the sampling plot area, which may have contributed to the resulting discrepancy between static and mobile measurements (Figs. 3 and 4). However, the spatial accuracy achieved with the current configuration of the mobile sensor system can be considered adequate and may provide a solid basis for the creation of high-resolution maps.

\section{Conclusions}

The results from the present study suggest that mobile multisensor systems, including ultrasonic and optical sensors, together with a precise GPS can produce acceptable accuracies for biomass assessment in extremely heterogeneous grassland. Such systems may, for example, facilitate mapping of larger grassland areas at high spatial position accuracy, allowing the identification of nested structures within the vegetation. However, our findings also show the limits even advanced sensor systems have in the assessment of biomass of extremely heterogeneous grasslands, which is e.g. typical for very leniently stocked pastures. Thus, it is necessary that further research be carried out to develop improved sensor systems for supporting practical grassland farming.

\section{Data availability}

The data presented in this paper are available on request from the corresponding author. 


\section{Appendix A: Abbreviations}

$\begin{array}{ll}\text { FM } & \text { fresh matter } \\ \text { FOV } & \text { field of view } \\ \text { GIS } & \text { geographic information system } \\ \text { GPS } & \text { global positioning system } \\ \text { USH } & \text { ultrasonic sward height } \\ \text { NDSI } & \text { normalized spectral vegetation index } \\ \text { NIR } & \text { near infrared } \\ \text { SLU } & \text { standard livestock unit } \\ \text { NDVI } & \text { normalized difference vegetation index } \\ \text { VI } & \text { vegetation index }\end{array}$

Appendix B: Assessment of position accuracy detailed information

To evaluate the position accuracy during mobile measurements within study plots $(50 \times 30 \mathrm{~m})$, wooden planks were placed at the end of each vehicle lane at the outer edge of the plot border (Fig. A1). With $120 \times 40 \times 11 \mathrm{~cm}$ (depth $\times$ width $\times$ height) targets had defined dimensions and allowed an unimpaired passage of the vehicle.

Position accuracy was assessed by identifying erroneous measurements with respect to apparent target edges. For this purpose the mounted ultrasonic sensors were used as they provide both high measurement densities along the lanes and sensitive reactions of the measurement signal at target detection. Depending on the field of view and the mount height of the sensor, targets were expected to be hit by the sound cone already at a distance of $12.5 \mathrm{~cm}$ on both sides of the target edges during passage, resulting in a total target detection range (apparent target area) of $36 \mathrm{~cm}$ width including the target depth of $11 \mathrm{~cm}$ (Fig. A2).

A data set was generated using USH measurements within a $25 \mathrm{~cm}$ distance around the apparent target edges (Fig. A3). Recordings were performed in the moderately grazed study plot in April 2014 before vegetation started to grow. The low canopy height at this time of the year ensured a sufficient discrimination between grassland canopy and targets. USH measurements at locations within the investigated distance $(n=920)$ were attributed with their specific distance to the apparent edge of the targets. Though targets had a defined height of $40 \mathrm{~cm}$, measured height values varied due to surface roughness and vehicle movements. This required the determination of the actual target height from the total data set of USH values and distinguishing this from the sward heights. For this purpose the data set was separated by using the inflection point of a height-sorted USH histogram to group and classify readings into low grassland (mean $=8.7$, $\mathrm{SD}= \pm 5.6$ ) and target (mean $=42.0, \mathrm{SD}= \pm 4.3$ ) members. Figure $\mathrm{A} 3$ presents an example of the classified readings and their respective locations, illustrating point density and compliance with target values.

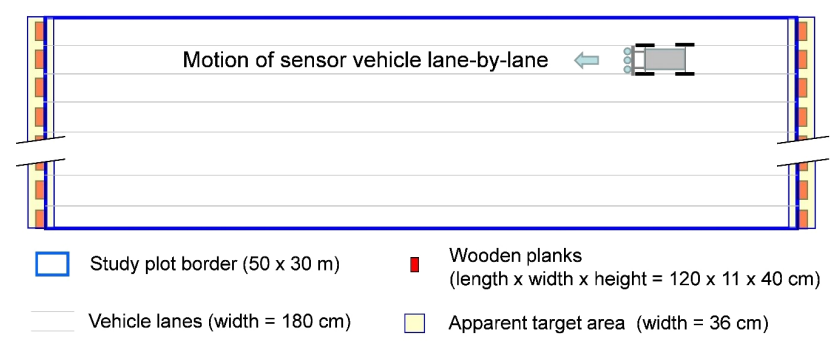

Figure B1. Display of reference targets (wooden planks) at the front ends of the study plot. Targets of defined dimensions and positions allowed the passage of the sensor vehicle moving lane-bylane.

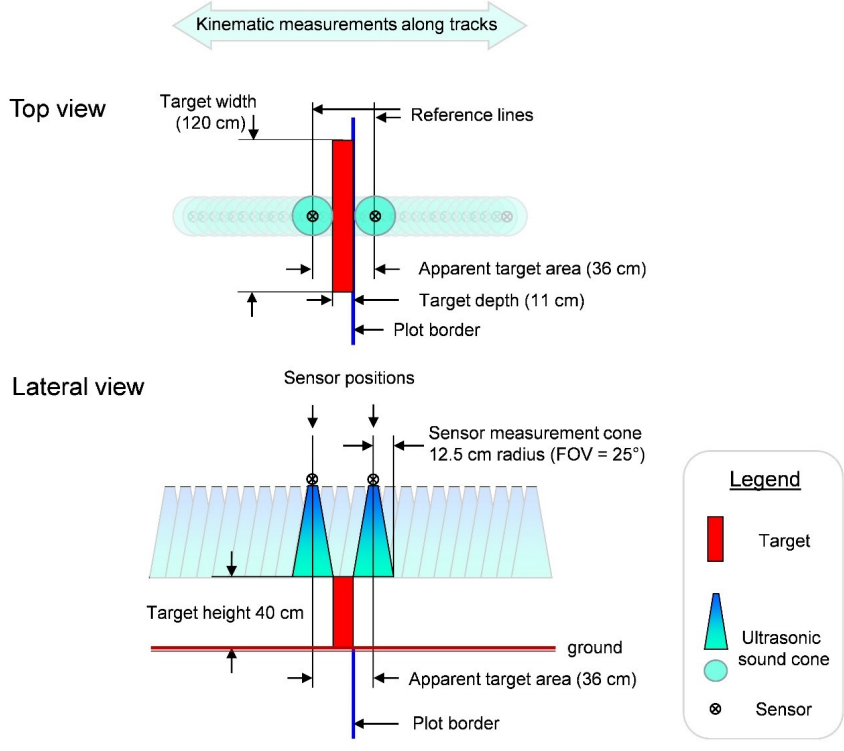

Figure B2. Display of a reference target, as used for assessing position accuracy and measured by ultrasonic sensors during passage of the vehicle. The two featured sensor positions show the distance range of expected target detection (apparent target area) independent of moving direction. These positions are used as reference lines for distinction and classification of correct and erroneous measurements. 


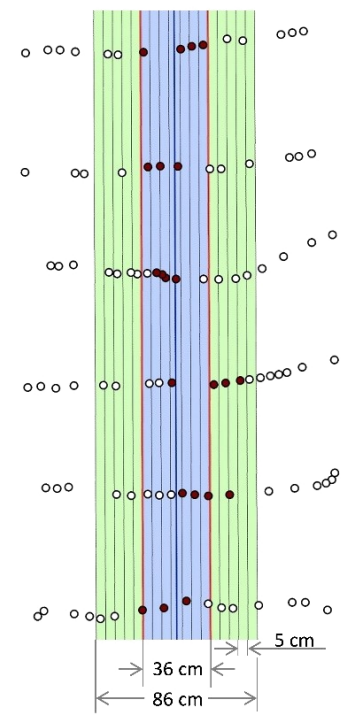

- Measurement points with USH readings below target height ${ }^{1)}$

- Measurement points with USH readings

- equal to or exceeding target height

Apparent target area

(considering target width, sensor field of view and mount height of sensor)

Sward area ${ }^{2)}$

(outside apparent target area)

Line of apparent target edge

(where a change in USH is expected from high to low values or vice versa)

1) Measured target height $=42.0 \pm 4.3 \mathrm{~cm}$

(mean \pm standard deviation)

2) Measured sward height $=8.7 \pm 5.6 \mathrm{~cm}$

(mean \pm standard deviation)

Figure B3. Locations of measurement points with USH readings generated by vehicle-mounted sensors during the passage of targets for determining position accuracy. The diagram exemplarily shows a $3.4 \times 1.7 \mathrm{~m}^{2}$ map extract of the moderately stocked grassland paddock (see Fig. 1). 
Author contributions. Michael Wachendorf and Thomas Fricke conceived and designed the experiments. Sensor measurements were performed under supervision of Hanieh Safari, Thomas Fricke and Björn Reddersen while reference value analysis were under supervision of Hanieh Safari. Data analysis and paper writing were done by Hanieh Safari with the support of Michael Wachendorf and Thomas Fricke. Björn Reddersen contributed valuable back ground information on data processing and analysis and actively supported the paper writing process. Thomas Möckel took part in the interpretation of results and contributed to the revision of the manuscript.

Acknowledgements. The authors would like to thank the division of Grassland Science, Georg-August-Universität Göttingen, for the provision of experimental pastures and their kind cooperation. Thanks to Andrea Gerke and Mansour Royan for their help in the field and data analysis. This project was supported by a grant of the Research Training Group 1397 "Regulation of soil organic matter and nutrient turnover in organic agriculture" of the German Research Foundation (DFG).

Edited by: M. J. da Silva

Reviewed by: two anonymous referees

\section{References}

Adamchuk, V. I., Hummel, J. V., Morgan, M. T., and Upadhyaya, S. K.: On-the-go soil sensors for precision agriculture, Comp. Elect. Agric., 44, 71-91, 2004.

Biewer, S., Fricke, T., and Wachendorf, M.: Determination of Dry Matter Yield from Legume-Grass Swards by Field Spectroscopy, Crop Sci., 49, 1927-1936, doi:10.2135/cropsci2008.10.0608, 2009a.

Biewer, S., Fricke, T., and Wachendorf, M.: Development of Canopy Reflectance Models to Predict Forage Quality of Legume-Grass Mixtures, Crop Sci., 49, 1917-1926, doi:10.2135/cropsci2008.11.0653, 2009b.

Blüthgen, N., Dormann, C. F., Prati, D., Klaus, V. H., Kleinebecker, T., Hölzel, N., Alt, F., Boch, S., Gockel, S., Hemp, A., Müller, J., Nieschulze, J., Renner, S. C., Schöning, I., Schumacher, U., Socher, S. A., Wells, K., Birkhofer, K., Buscot, F., Oelmann, Y., Rothenwöhrer, C., Scherber, C., Tscharntke, T., Weiner, C. N., Fischer, M., Kalko, E. K. V., Linsenmair, K. E., Schulze, E.-D., and Weisser, W. W.: A quantitative index of land-use intensity in grasslands: Integrating mowing, grazing and fertilization, Basic Appl. Ecol., 13, 207-220, 2012.

Castle, M. E.: A simple disc instrument for estimating herbage yield, J. Br. Grassl. Soc., 31, 37-40, doi:10.1111/j.13652494.1976.tb01113.x, 1976.

Cozzolino, D., Porker, K., and Laws, M.: An Overview on the Use of Infrared Sensors for in Field, Proximal and at Harvest Monitoring of Cereal Crops, Agriculture 2015, 5, 713-722, doi:10.3390/agriculture5030713, 2015.

Diaconis, P. and Efron, B.: Computer-intensive methods in statistics, Sci. Am., 248, 96-108, 1983.

Duan, M., Gao, Q., Wan, Y., Li, Y., Guo, Y., and Ganzhu, Z.: Biomass estimation of alpine grasslands under different grazing intensities using spectral vegetation indices, Can. J. Remote Sens., 37, 413-421, doi:10.5589/m11-050, 2014.
Farooque, A. A., Chang, Y. K., Zaman, Q. U., Groulx, D., Schumann, A. W., and Esau, T. J.: Performance evaluation of multiple ground based sensors mounted on a commercial wild blueberry harvester to sense plant height, fruit yield and topographic features in real-time, Comput. Electron. Agr., 91, 135-144, doi:10.1016/j.compag.2012.12.006, 2013.

Fava, F., Colombo, R., Bocchi, S., Meroni, M., Sitzia, M., Fois, N., and Zucca, C.: Identification of hyperspectral vegetation indices for Mediterranean pasture characterization, Int. J. Appl. Earth Obs., 11, 233-243, doi:10.1016/j.jag.2009.02.003, 2009.

Fricke, T. and Wachendorf, M.: Combining ultrasonic sward height and spectral signatures to assess the biomass of legume-grass swards, Comput. Electron. Agr., 99, 236-247, doi:10.1016/j.compag.2013.10.004, 2013.

Fricke, T., Richter, F., and Wachendorf, M.: Assessment of forage mass from grassland swards by height measurement using an ultrasonic sensor, Comput. Electron. Agr., 79, 142-152, doi:10.1016/j.compag.2011.09.005, 2011.

Goel, N. S.: Models of vegetation canopy reflectance and their use in estimation of biophysical parameters from reflectance data, Remote Sens., 4, 1-212, doi:10.1080/02757258809532105, 1988.

Gottfried, T., Auerswald, K., and Ostler, U.: Mobile correction for a spatial offset between sensor and position data in on-the-go sensor applications, Comput. Electron. Agr., 84, 76-84, 2012.

Hakl, J., Hrevušová, Z., Hejcman, M., and Fuksa, P.: The use of a rising plate meter to evaluate Lucerne (Medicago sativa L.) height as an important agronomic trait enabling yield estimation, Grass Forage Sci., 67, 589-596, 2012.

Himstedt, M., Fricke, T., and Wachendorf, M.: Determining the contribution of legumes in legume-grass mixtures using digital image analysis, Crop Sci., 49, 1910-1916, doi:10.2135/cropsci2008.11.0636, 2009.

Inoue, Y., Penuelas, J., Miyata, A., and Mano, M.: Normalized difference spectral indices for estimating photosynthetic efficiency and capacity at a canopy scale derived from hyperspectral and $\mathrm{CO}_{2}$ flux measurements in rice, Remote Sens. Environ., 112, 156-172, doi:10.1016/j.rse.2007.04.011, 2008.

Isselstein, J., Jeangros, B., and Pavlu, V.: Agronomic aspects of biodiversity targeted management of temperate grasslands in Europe - A review, Agr. Res., 3, 139-151, 2005.

Kawamura, K., Betteridge, K., Sanches, I. D., Tuohy, Mike P., Costall, D., and Inoue, Y.: Field radiometer with canopy pasture probe as a potential tool to estimate and map pasture biomass and mineral components: A case study in the Lake Taupo catchment, New Zealand, New Zeal. J. Agr. Res., 52, 417-434, doi:10.1080/00288230909510524, 2009.

Kristensen, T., Søegaard, K., and Kristensen, I. S.: Management of grasslands in intensive dairy livestock farming, Livest Prod Sci., 96, 61-73, doi:10.1016/j.livprodsci.2005.05.024, 2005.

Lan, Y., Zhang, H., Lacey, R., Hoffmann, W. C., and Wu, W.: Development of an Integrated Sensor and Instrumentation System for Measuring Crop Conditions, Agricultural Engineering International: the CIGR E Journal, Manuscript IT 08 1115, Vol. XI, April, 2009.

Muñoz-Huerta, R. F., Guevara-Gonzalez, R. G., Contreras-Medina, L. M., Torres-Pacheco, I., Prado-Olivarez, J., and OcampoVelazquez, R. V.: A Review of Methods for Sensing the Nitrogen Status in Plants: Advantages, Disadvantages and Recent 
Advances, Sensors, 13, 10823-10843, doi:10.3390/s130810823, 2013.

Nagasaka, Y., Umeda, N., Kanetai, Y., Taniwaki, K., and Sasaki Y.: Autonomous guidance for rice transplanting using global positioning and gyroscopes, Comput. Electron. Agr., 43, 223-234, 2004.

Nelder, J. A.: The statistics of linear models: back to basics, Stat Comput., 4, 221-234, doi:10.1007/BF00156745, 1994.

Numata, I., Roberts, D., Chadwick, O., Schimel, J., Galvao, L., and Soares, J.: Evaluation of hyperspectral data for pasture estimate in the Brazilian Amazon using field and imaging spectrometers, Remote Sens. Environ., 112, 1569-1583, doi:10.1016/j.rse.2007.08.014, 2008.

Oudshoorn, F. W., Cornou, C., Hellwing, A. L. F., Hansen, H. H., Munksgaard, L., Lund, P., and Kristensen, T.: Estimation of grass intake on pasture for dairy cows using tightly and loosely mounted di- and tri-axial accelerometers combined with bite count, Comput. Electron. Agr., 99, 227-235, doi:10.1016/j.compag.2013.09.013, 2013.

Pepperl, F.: Sensors for the factory automation - Overview Standard Sensors, Pepperl+Fuchs ENU Part No. 200237, available from: http://www.pepperl-fuchs.us/usa/downloads_USA/ Sensing-your-needs-2010-01-EN.pdf, 2010.

Pittman, J. J., Arnall, D. B., Interrante, S. M., Moffet, C. A., and Butler, T. J.: Estimation of biomass and canopy height in bermudagrass, alfalfa, and wheat using ultrasonic, laser, and spectral sensors, Sensors, 15, 2920-2943, doi:10.3390/s150202920, 2015.

Pullanagari, R. R., Yule, I. J., Hedley, M. J., Tuohy, M. P., Dynes, R. A., and King, W. M.: Multi-spectral radiometry to estimate pasture quality components, Precis. Agric., 13, 442-456, doi:10.1007/s11119-012-9260-y, 2012.

Psomas, A., Kneubühler, M., Huber, S., Itten, K., and Zimmermann, N. E.: Hyperspectral remote sensing for estimating aboveground biomass and for exploring species richness patterns of grassland habitats, Int. J. Remote Sens., 32, 9007-9031, doi:10.1080/01431161.2010.532172, 2011.

R Development Core Team, R.: A Language and Environment for Statistical Computing, The R Foundation for Statistical Computing, Vienna, Austria, ISBN 3-900051-07-0, available at: http: //www.R-project.org/, 2013.

Rahman, M. M., Lamb, D. W., Stanley, J. N., and Trotter, M. G.: Use of proximal sensors to evaluate at the sub-paddock scale a pasture growth-rate model based on light-use efficiency, Crop Pasture Sci., 65, 400-409, doi:10.1071/CP14071, 2014.
Raymond, H. E.: Airborne remote sensing of canopy water thickness scaled from leaf spectrometer data, Int. J. Remote Sens., 12, 643-649, doi:10.1080/01431169108929679, 1991.

Reddersen, B., Fricke, T., and Wachendorf, M.: A multisensor approach for predicting biomass of extensively managed grassland, Comput. Electron. Agr., 109, 247-260, doi:10.1016/j.compag.2014.10.011, 2014.

Rook, A. and Tallowin, J.: Grazing and pasture management for biodiversity benefit, Anim. Res., 52, 181-189, doi:10.1051/animres:2003014, 2003.

Ryan, T. P.: Modern regression methods, John Wiley \& Sons, Vol. 655, 2008.

Safari, H., Fricke, T., and Wachendorf, M.: The potential of ultrasonic and hyperspectral sensor combination for the estimation and mapping of pasture biomass, Mitt. Gesell. Pflanzenbauwissenschaften, 27, 139-142, 2015.

Safari, H., Fricke, T., and Wachendorf, M.: Determination of fibre and protein content in heterogeneous pastures using field spectroscopy and ultrasonic sward height measurements, Comput. Electron. Agr., 123, 256-263, doi:10.1016/j.compag.2016.03.002, 2016.

Schellberg, J., Hill, M. J., Gerhards, R., Rothmund, M., and Braun, M.: Precision agriculture on grassland: Applications, perspectives and constraints, Eur. J. Agron., 29, 59-71, doi:10.1016/j.eja.2008.05.005, 2008.

Silvia Cid, M., Miguel, A., and Bizuela Cid, B.: Heterogeneity in tall fescue pastures created and sustained by cattle grazing, Range Manage., 6, 644-649, 1998.

Suzuki, Y., Okamoto, H., Takahashi, M., Kataoka, T., and Shibata, Y.: Mapping the spatial distribution of botanical composition and herbage mass in pastures using hyperspectral imaging, Grassl. Sci., 58, 1-7, doi:10.1111/j.1744-697X.2011.00239.x, 2012.

Wrage, N., Strodthoff, J., Cuchillo, H., Isselstein, J., and Kayser, M.: Phytodiversity of temperate permanent grasslands: ecosystem services for agriculture and livestock management for diversity conservation, Biodivers. Conserv., 20, 3317-3339, 2011.

Wrage, N., Şahin Demirbağ, N., Hofmann, M., and Isselstein, J.: Vegetation height of patch more important for phytodiversity than that of paddock, Agr. Ecosyst. Environ., 155, 111-116, doi:10.1016/j.agee.2012.04.008, 2012.

Zhao C., Huang, W., Chen, L., Meng, Z., Wang, Y., and Xu, F.: A harvest area measurement system based on ultrasonic sensors and DGPS for yield map correction, Precis Agric., 11, 163-180, 2010 . 